\title{
LIVRO DIDÁTICO DO PNLD CAMPO: CONSIDERAÇÕES SOBRE ENSINO DE HISTÓRIA EM ESCOLAS LOCALIZADAS NO CAMPO
}

\author{
TEXTBOOK FROM PNLD CAMPO: IDEAS ABOUT HISTORY TEACHING ON \\ SCHOOLS IN RURAL AREAS
}

Rita de Cássia Gonçalves ${ }^{1}$

Geyso Dongley Germinari²

\begin{abstract}
RESUMO: O presente artigo debate o lugar do livro didático de História nas escolas localizadas no campo, a partir de dados levantados em pesquisa realizada com professores dos anos iniciais do Ensino Fundamental de nove escolas da região metropolitana de Curitiba (PR). Os sujeitos da pesquisa foram acompanhados no processo de escolha, em 2015, 2016 e 2017, para discussão e debate sobre o processo de recebimento e utilização da coleção escolhida. Além disso, discutem-se os critérios de escolha e a apreciação crítica dos professores da obra "Coleção Novo Girassol: Saberes e Fazeres do Campo", indicado pelo Programa Nacional do Livro Didático do Campo (PNLD Campo) de 2016. É premente pensar as questões que envolvem a distribuição, escolha e uso dos livros didáticos do PNLD Campo, tendo em conta o lugar de destaque das obras didáticas na cultura escolar e nos processos de ensino e aprendizagem. A pesquisa tem como objetivo discutir o processo de escolha, buscando compreender se o material atende as especificidades do público destas escolas. Para tanto, apresenta breve panorama relacionado ao livro didático de História, contextualizando as pesquisas no Brasil, nas últimas décadas; retoma as discussões acerca do PNLD, bem como sobre o ensino de História presentes na coleção utilizada e, por fim, tece considerações sobre o ensino de História e o livro didático de História trazido por este programa para as escolas e as implicações nos processos de ensino e aprendizagem desta disciplina. Do ponto de vista teórico, a análise tomou como referência estudos de pesquisadores da Educação Histórica, como Rüsen (2001, 2007, 2010a, 2010b, 2012) e Lee (2006); em investigações sobre o livro didático de Munakata (1997, 2010, 2012) e Bittencourt (1993, 1997, 2008, 2011); e em pesquisas da Educação do Campo de Munarim (2010). A pesquisa permitiu compreender aspectos da relação que professores de escolas do campo mantém com o livro didático selecionado a partir da indicação do PNLD Campo 2016.
\end{abstract}

Palavras-chave: Livro Didático. História. Ensino. Professores. Educação Histórica.

\footnotetext{
${ }^{1}$ Professora adjunta do Programa de Pós-Graduação em Educação da Universidade Tuiuti do Paraná - PPGE/UTP professoraritadecassia@gmail.com - rita.goncalves@utp.br 41 98835-2477.

2 Professor do Departamento de História e dos Programas de Pós-Graduação em Educação e História da Universidade Estadual do Centro-Oeste (UNICENTRO), campus Irati. Coordenador do Laboratório de Ensino de História (LEHIS-UNICENTRO). É coordenador do Grupo Pesquisa Educação Histórica: Consciência Histórica e Cultura (UNICENTRO-CNPq). Doutor em Educação pela Universidade Federal do Paraná (UFPR). E-mail: geysog@gmail.com
} 
ABSTRACT: The purpose of this article is to discuss history teaching starting from discussions proposed from research developed with teachers from a municipality in the metropolitan region of Curitiba (Paraná, Brazil), who used the PNLD Campo - 2016, more specifically the History textbook from Elementary School. The subjects of this research were followed up in the selection for discussion and debate on the process of receiving and using the chosen collection during the years of 2015, 2016 and 2017. In addition, the selection criteria and the critical appreciation of the teachers of the "Novo Girassol: Saberes e Fazeres do Campo" Collection, indicated by the National Book and Teaching Material Program of 2016 (PNLD Campo), are discussed. It is imperative to think about these topics, which involve the distribution, choice and use of PNLD Campo textbooks, taking into account the prominent place of the didactic works in the school culture and in the teaching and learning processes. The research aims to discuss the selection process, in order to understand if the material embraces the public specificities and context of these schools. In this sense, it presents a brief panorama related to the History textbook, contextualizing the development of researches in Brazil, in the last decades. It also resumes the discussions about the PNLD and the questions regarding the history teaching and textbook present in the collection used in the schools located in the rural areas in this municipality and finally, it weaves considerations on History teaching and learning and history textbook brought by this program to the schools. The theoretical foundation is based on the analysis from studies of historical education researchers, such as Jörn Rüsen (2001, 2007, 2010a, 2010b, 2012) and Peter Lee (2006). In relation to the studies of didactic books it is used the concepts of Kazumi Munakata (1997, 2010, 2012) and Circe M. Bittencourt (1993, 1997, 2008, 2011). And last, regarding to education on rural areas it is used the studies of Antonio Munarim (2010). The research allowed to comprehend aspects of the relationship that teachers of rural schools maintains with the textbook selected from the indication of PNLD Campo 2016.

Keywords: Textbook. History. Teaching. Teachers. History Education.

\section{Introdução}

Estudos sobre o livro didático têm se desenvolvido com grande impulso nos últimos quarenta anos e atraído interesse de investigadores de diversos países, sendo que as pesquisas apresentam perspectivas de análises que privilegiam o lugar do livro didático na cultura escolar, as questões teóricas e metodológicas do processo de ensino-aprendizagem e as políticas de produção e distribuição deste material.

O pesquisador Kazumi Munakata (2012) destaca que a expansão das investigações a respeito do livro didático não foi apenas um fenômeno brasileiro, mas uma realidade internacional, tanto que, em vários países, foram se organizando centros de pesquisa sobre o tema, entre as décadas de 1980 e 2000. 
A preocupação investigativa com os livros didáticos se justifica pelo crescente uso desses materiais em sala de aula, bem como pelo aumento do alcance dos programas de sua seleção e distribuição, implementados pelos governos federais desde 1996. As mudanças na legislação, a produção editorial e a distribuição em larga escala para escolas públicas transformaram o Brasil no maior consumidor de livros didáticos do mundo. O uso em larga escala tem delimitado, em alguns casos, o que e quando determinados conteúdos curriculares são trabalhados na Educação Básica.

Este artigo apresenta resultados de pesquisa ${ }^{3}$ desenvolvida com professores do Ensino Fundamental de escolas localizadas no campo, de um município da região metropolitana de Curitiba (PR), os quais participaram de dois processos do Programa Nacional do Livro Didático do Campo (PNLD Campo) de 2013 e 2016 e que receberam a coleção disponibilizada e apresentada no Guia PNLD Campo 2016 - Educação do Campo - Ensino Fundamental - Anos Iniciais ${ }^{4}$. Cabe ressaltar que o Programa foi descontinuado e, no ano de 2019, todas as escolas cadastradas como escolas rurais junto ao censo escolar ${ }^{5}$ receberam coleções distribuídas para todas as outras escolas, classificadas como urbanas, de anos iniciais do Brasil.

Os sujeitos da pesquisa foram os professores dos anos iniciais do Ensino Fundamental que atuam em todas as séries de nove das dez escolas municipais localizadas no campo de um município da região metropolitana de Curitiba. Esses profissionais participaram do processo de escolha da coleção de livro didático, indicada pelo PNLD Campo 2016, para uso em sala de aula. A investigação consistiu no acompanhamento da ação dos professores, desde a escolha da obra até o uso em sala de aula. Todo esse processo ocorreu entre 2015 e 2017. Em encontros com todos os professores (72 professores) participantes da pesquisa realizaram-se discussões e debates sobre o processo de recebimento e utilização da coleção escolhida. Os professores também concederam entrevistas durante os momentos de hora atividade e nelas expressaram suas ideias e concepções acerca da coleção didática selecionada.

\footnotetext{
${ }^{3}$ Esta pesquisa é financiada com recursos do CNPq - Chamada Universal MCTI/CNPq n.0 01/2016.

${ }^{4}$ Disponível em: http://www.fnde.gov.br/component/k2/item/6575-guia-pnld-campo-2016-

\%E2\%80\%93-anos-iniciais-do-ensino-fundamental. Acesso em: 25 set. 2018.

${ }^{5}$ Dados disponíveis em: http://inep.gov.br/censo-escolar. Acesso em: 27 set. 2018.
} 
Desse modo, a pesquisa teve como propósito investigar o processo do PNLD Campo, desde a escolha da coleção ao uso em sala de aula, buscando compreender pela perspectiva dos professores se este material atende as especificidades do público que frequenta as escolas localizadas no campo.

O componente curricular de História, o qual está inserido na coleção do PNLD Campo 2016 e que foi escolhido, em conjunto, pelos professores foi "Novo Girassol: Saberes e Fazeres do Campo", da Editora FTD. A obra é organizada por onze volumes direcionados ao aluno e outros onze específicos para o professor. É uma coleção seriada interdisciplinar, constituída de livros com os componentes Letramento e Alfabetização e Alfabetização Matemática para o primeiro ano; Letramento e Alfabetização, História e Geografia e Alfabetização Matemática e Ciências para segundo e terceiro anos; Língua Portuguesa, História e Geografia, e Matemática e Ciências para quarto e quinto anos.

Com a intenção de problematizar as especificidades do livro didático de História produzido para escolas localizadas no campo e as implicações para os processos de ensino e aprendizagem desta disciplina, o presente artigo foi dividido em três momentos. O primeiro apresenta um breve panorama relacionado ao livro didático de História, contextualizando o desenvolvimento das pesquisas no Brasil, nas últimas décadas. A seguir, retomam-se as discussões acerca do PNLD e as questões a respeito do ensino de História presentes na coleção utilizada nas escolas participantes da presente pesquisa. Por fim, tecemse considerações em relação ao ensino e à aprendizagem de História e o livro desta disciplina trazido pelo Programa para a escola.

\section{Pesquisas e Livros Didáticos de História}

O livro didático de História, de acordo com Zamboni (2005), está entre os temas mais investigados e os estudos podem ser agrupados a partir de alguns problemas de pesquisa, tais como: 1. Práticas de leituras e formas de apropriação dos livros didáticos; 2. Circulação e estratégias editoriais; 3. História da disciplina e livros didáticos; 4. Livros didáticos de História: conteúdos e tendências historiográficas. Tal perspectiva é atestada em outras investigações 
teóricas como as de Bittencourt (1993, 1997, 2008, 2011); Fonseca (2011) e Munakata $(1997,2010,2012)$.

A pesquisa concernente ao livro didático de História insere-se no campo maior de investigações acerca do ensino de História, o qual se desenvolveu no Brasil marcadamente a partir da década de 1980, durante o processo político de redemocratização, que levou ao fim do regime militar (1964-1985), período de intenso debate sobre a retomada da autonomia da disciplina de História e que culminou em um movimento de renovação da concepção de História e da prática de ensino/pesquisa.

Tal movimento levou a criação de espaços, nos cursos de graduação, voltados à reflexão no que tange à prática do ensino de História; à organização de encontros nacionais para discussão e à mudanças curriculares, implementadas em diversos estados. Nesse contexto, também ocorreram modificações nos livros didáticos e no programa de distribuição de livros pelo governo federal. Assim, de modo amplo:

As experiências pedagógicas, a formação do profissional de História; a produção do conhecimento histórico na escola, o significado da utilização e a análise dos conteúdos do livro didático; o ensino de História temática como proposta para romper com o ensino de História tradicional; reformas curriculares e a utilização em sala de aula de novas linguagens (música, fotografia, literatura, filmes, história em quadrinhos) passaram a ser objeto de reflexão e pesquisa. (GERMINARI, 2016, p. 762).

Desde o final do século $X X$, a produção de investigações sobre o ensino de História aumentou de modo significativo e grande parte dela está relacionada as pesquisas acerca do livro didático. Thais Nivia de Lima e Fonseca (2011) identificou 80 trabalhos que abordaram o ensino de História, produzidos entre 1988 e 2002, entre dissertações, teses, artigos e textos apresentados em congressos. Uma amostra desses trabalhos foi analisada pela pesquisadora, a qual identificou que:

Cerca de $66 \%$ dos estudos levantados concentram-se nos temas dos currículos e programas para o ensino de História, das práticas escolares no ensino de História e do livro didático de História, estando este último tema na liderança, com quase $40 \%$ dos 
trabalhos analisados. Dentro desses três temas, alguns subtemas se destacam, como a formação cívica e nacionalista no ensino de História e as relações entre este ensino e a historiografia, ambos representando cerca de $33 \%$ dos trabalhos, e também a história das mulheres nos livros didáticos, reformas curriculares, produção técnico do livro didática. (FONSECA, 2011, p. 30).

As primeiras investigações, na década de 1960, a respeito do livro didático de História destacaram o caráter ideológico dos materiais, a partir da relação entre sua produção e a sociedade capitalista, a relação entre o conteúdo apresentado e a ideologia de estado. Nessa perspectiva, muitos estudos fundamentados nas ideias do historiador francês Marc Ferro ${ }^{6}$ identificaram as relações entre livro didático e a constituição de uma memória coletiva da sociedade. A pesquisadora Circe Maria Fernandes Bittencourt (2011, p. 497) destaca que:

\begin{abstract}
Marc Ferro identificou o caráter ideológico da literatura didática de maneira muito semelhante em países de diferentes lugares nas décadas de 1960 e 1970 concluindo que os livros escolares eram veículos privilegiados da difusão de uma ideologia e de uma manipulação política sobre as populações dos países do então denominado Terceiro Mundo.
\end{abstract}

As pesquisas desenvolvidas nas últimas décadas privilegiam outras abordagens, como a compreensão do livro enquanto mercadoria, as relações entre conteúdo escolar e métodos de aprendizagem, a importância das grandes empresas produtoras de livros didáticos, as articulações entre políticas públicas educacionais e os processos de escolha dos livros pelos professores, os usos que professores e alunos fazem do material e as novas tecnologias incorporadas ao seu uso.

\title{
2. O Programa Nacional do Livro Didático do Campo e o Ensino de História
}

A Carta Constitucional de 1988, conhecida como Constituição Cidadã, documento importante no processo de redemocratização e de estabelecimento da democracia brasileira pós-ditadura militar, dispõe, em seu artigo 205, que a Educação é um direito de todos e dever do Estado e da família e deve visar o

${ }^{6}$ Ver: (FERRO, 1983). 
pleno desenvolvimento da pessoa, seu preparo para o exercício da cidadania e sua qualificação para o trabalho (BRASIL, 1988), um direito inalienável, universal e integral. Dentro deste contexto,

A Lei 9394 (1996) - Lei de Diretrizes e Bases da Educação Nacional - é assinada partindo do pressuposto constitucional que a Educação é dever do Estado. Os debates que ocorrem desde sua assinatura se concentram em garantir um ensino público de qualidade dentro de padrões mínimos. (GERMINARI; GONÇALVES, 2016, p. 61).

Mesmo existindo programa governamental relacionado ao livro didático desde 1938, instituído na gestão do Ministro da Educação Gustavo Capanema, por meio do Decreto-Lei 1006 de 30/12/1938, o qual criava a Comissão Nacional do Livro Didático (OLIVEIRA, 1984), foi somente na década de 1990 que os livros didáticos distribuídos para alunos da rede pública de ensino começaram a passar por um processo prévio de avaliação, antes da escolha dos professores. De acordo com Rita de Cássia Gonçalves Pacheco dos Santos (2013, p. 147):

[...] Em 1996 foi iniciado o processo de avaliação pedagógica dos livros didáticos a serem utilizados nas escolas públicas de Ensino Fundamental, procedimento que é aplicado até hoje em todos os programas para o livro didático do governo federal. Os livros que apresentam erros conceituais, indução a erros, desatualização, preconceito ou discriminação a partir de então passam a ser excluídos da lista de livros publicados no Guia do Livro Didático.

Desde o início do século XXI, o governo federal buscou aprimorar a entrega de materiais didáticos aos alunos da Educação Básica, a fim de atender ao artigo 208 da Constituição Federal, que dispõe sobre a obrigatoriedade da Educação Básica dos 4 aos 17 anos e do atendimento ao educando em todas as etapas de formação "por meio de programas suplementares de material didático escolar" (BRASIL, 1988, grifo dos autores).

Além de ofertar livros aos estudantes de todos os anos do Ensino Fundamental, o governo federal instituiu programas para atender as necessidades de aprendizagem, como, por exemplo, o Programa Nacional do Livro do Ensino Médio (PNLEM), que visava à distribuição de livros para os alunos do Ensino Médio; o Programa Nacional do Livro Didático para a Educação de 
Jovens e Adultos (PNLD EJA); o PNLD de obras complementares; o PNLD Alfabetização na Idade Certa, bem como programas de fornecimento de dicionários de Língua Portuguesa e o PNLD Campo.

\begin{abstract}
O propósito de fornecer livros didáticos a todos os alunos do Brasil responde à necessidade de melhoria dos níveis educacionais em todo o território nacional. O livro didático é um artefato cultural presente na cultura escolar e considerado parte importante do processo educativo (SANTOS, 2013, p. 147).
\end{abstract}

O PNLD Campo, portanto, resulta do processo de lutas dos movimentos sociais por uma educação que responda as necessidades dos povos do campo na busca pela emancipação. A Educação do Campo teve suas origens no final dos anos 1980 e nas palavras de Antonio Munarim veio para provar que, muito mais que luta por escola, busca "reconhecer e fortalecer o processo de resistência e emancipação dos povos do campo. E nessa estratégia, as lutas por políticas públicas que garantam o seu direito à educação, preconizam uma educação no campo que seja do campo" (MUNARIM, 2010, p. 12).

O PNLD Campo ${ }^{7}$ começou a ser distribuído no ano letivo de 2013, porém o processo de elaboração teve início quatro anos antes com a publicação do edital para a produção de material e respondeu as reinvindicações dos movimentos sociais por coleções didáticas que reconhecessem as particularidades das populações do campo, nas quais crianças e jovens frequentam escolas classificadas como rurais, de acordo com os dados coletados e publicados anualmente pelo Instituto Nacional de Estudos e Pesquisas Educacionais Anísio Teixeira (INEP). No último censo, publicado no ano de 2018, o número de matrículas iniciais em escolas rurais, estaduais e municipais do Ensino Fundamental supera a casa de dois milhões de alunos ${ }^{8}$. O resultado demonstra a importância destas instituições para o desenvolvimento de um programa específico que dê conta das especificidades de sua realidade.

Em 2016, as escolas receberam as coleções desenvolvidas e selecionadas pelo Programa, as quais foram distribuídas para todas as escolas públicas

\footnotetext{
${ }^{7}$ Maiores informações podem ser encontradas em: http://www.fnde.gov.br/programas/programasdo-livro/consultas/editais-programas-livro/item/5373-edital-pnld-campo-2016. Acesso em: 24 set. 2018.

${ }^{8}$ Disponível em: http://portal.inep.gov.br/resultados-e-resumos. Acesso em: 25 set. 2018.
} 
(municipal, estadual e distrital) cadastradas como escolas rurais no site Data Escola e que firmaram o termo de adesão ao PNLD Campo.

É importante também destacar que a relação livro didático e Educação do Campo tem sido objeto de pesquisas sistematizadas em teses e dissertações. Dentre os vários trabalhos produzidos na área, a tese "A presença do livro didático de história em aulas do ensino médio: estudo etnográfico em uma escola do campo", de Edilson Aparecido Chaves (2015), investigou as formas de uso do livro didático em aulas de História em uma escola do campo do município de São José dos Pinhais (PR). A pesquisa priorizou o ponto de vista dos alunos do Ensino Médio acerca das relações do livro didático de História - disponibilizado pelo Programa Nacional do Livro Didático (PNLD) de 2012 - e a construção do conhecimento histórico. Este trabalho exemplifica a fertilidade da temática livro didático de História e a Educação do Campo. De acordo com Rita de Cássia Gonçalves Pacheco dos Santos (2013, p. 151):

\begin{abstract}
A obra didática desse modo faz parte do currículo escolar que é construído no e para o espaço da escola [que] é entendida como um instrumento que articula os saberes socialmente construídos no processo do conhecimento científico e os conteúdos e objetivos do ensino e da aprendizagem escolar.
\end{abstract}

O processo de seleção das obras didáticas ocorreu no município da região metropolitana de Curitiba analisado, de forma conjunta e democrática, em encontros proporcionados pelas direções das escolas e pela Secretaria da Educação. A escolha foi realizada somente no penúltimo dia indicado para que as escolas enviassem o pedido ao Fundo Nacional de Desenvolvimento da Educação (FNDE). Uma das razões foi que as coleções não chegaram na Secretaria da Educação, tampouco nas escolas. Aliás, esse foi um dos motivos alegados para que todo o processo de distribuição fosse centralizado na Secretaria, haja visto que o acesso às escolas poderia ser difícil, o que geraria atrasos na entrega.

Nos encontros foram criados critérios de seleção dos livros didáticos de História com base nas ideias apresentadas por Jörn Rüsen (2010b, p. 109-129), no texto "O livro didático ideal", o qual foi discutido com os professores antes de analisarem e selecionarem as coleções. Segundo Rüsen (2010b), um bom livro didático precisa apresentar quatro características principais: formato claro; 
estrutura didática clara; relação produtiva com o aluno e relação com a prática em sala de aula. Cabe ressaltar que o processo formativo dos professores auxiliou nas discussões, nas análises e na escolha do material didático a ser utilizado.

As coleções aprovadas e disponíveis para a escolha dos professores foram analisadas juntamente com o "Guia de Livros Didáticos PNLD Campo 2016 Anos Iniciais do Ensino Fundamental ${ }^{9 \prime}$. Somente duas coleções de editoras paulistas constaram no Guia: a coleção "Coleção Novo Girassol: Saberes e Fazeres do Campo", publicada pela Editora FTD, composta por 11 volumes (Livro do Aluno) e 11 Manuais do Educador. Também foi disponibilizada a "Coleção Campo Aberto" da Editora Global, a qual também foi composta pelo mesmo número de volumes. Após debate entre os professores, decidiu-se que as escolas do município adotariam a "Coleção Novo Girassol: Saberes e Fazeres do Campo". A construção coletiva de critérios de escolha dos livros didáticos de História torna-se atividade imprescindível, uma vez que estes materiais ocupam importante lugar no processo de ensino e aprendizagem e, de modo mais amplo, participam da vida dos estudantes. Pesquisas afirmam que o livro didático é, por vezes, um dos únicos artefatos culturais disponíveis para a prática de leitura dos alunos, assim, entende-se a importância do programa federal de acesso ao livro didático.

A reflexão sobre livro didático e aprendizagem histórica, na perspectiva de Rüsen (2010b) efetiva-se quando passar a ser significativa para o sujeito, e permite perspectivar a realidade com sentido histórico de modo consciente. Assim, aprender História, não significa, de modo algum, o mero acúmulo estéril de informações acerca do passado, sem relações intrínsecas com a vida cotidiana. O ensino e aprendizagem de História no espaço escolar na concepção ruseniana da formação da consciência histórica requer a produção de conhecimento histórico significativo e útil para vida dos estudantes, e que produza um senso da própria identidade. De acordo com Lee (2006, p. 135), em outros termos, "tal conhecimento não deve ser inerte, mas deve agir como uma parte da vida do aprendiz".

\footnotetext{
${ }^{9}$ Disponível em: http://www.fnde.gov.br/programas/livro-didatico/guias-do-pnld/item/6575-guiapnld-campo-2016-\%E2\%80\%93-anos-iniciais-do-ensino-fundamental. Acesso em: 30 jun. 2017.
} 
Entre os vários aspectos que envolvem o ensino e a aprendizagem de História no âmbito escolar, o livro didático de História merece atenção especial. O uso desses materiais em sala de aula tem crescido, impulsionado nas últimas décadas pelo Programa Nacional do Livro e do Material Didático (PNLD), cuja função é avaliar e disponibilizar obras didáticas, literárias e outros materiais pedagógicos para escolha dos professores de escolas públicas de educação básica das redes federal, estadual, municipal e distrital ${ }^{10}$. Segundo Oliveira et al. (2007, p. 54), "o Brasil é o país que mais investe na aquisição de livros didáticos para o ensino básico no mundo. São centenas de milhões de exemplares distribuídos, gratuitamente, para escolas públicas dos Ensinos Fundamental e Médio de todas as regiões".

A distribuição de livros didáticos pelo PNLD abrange todo território nacional e contempla todos os sistemas públicos de ensino. Em suma, estes materiais estão presentes em praticamente todas as escolas públicas. Isaíde Bandeira Timbó (2007, p. 64) destaca que "[...] é imprescindível problematizar o que será ensinado, por exemplo, a partir do que consta nos livros didáticos [...]", pois, o acesso ampliado aos livros didáticos tem influenciado à seleção de conteúdos e os modos de ensinar e aprender História na escola. Nesse sentido,

[...] a complexidade e a centralidade do livro didático na organização do trabalho didático-pedagógico e na prática de sala de aula têm atraído o interesse de pesquisadores de vários países. Esse material didático vem sendo investigado sob diferentes ângulos teórico-metodológicos, os quais abrigam análises diacrônicas e de problemas atuais do ensino-aprendizagem em várias áreas de conhecimento. (GERMINARI; MOURA, 2017, p. 103).

As ideias de Rüsen $(2007,2012)$ e Lee (2006) indicam caminhos para refletir acerca dos problemas atuais no que se refere a relação aprendizagem histórica e livros didáticos. As suas contribuições teóricas permitem indagar a estrutura epistemológica que permeia os conteúdos dos livros didáticos de História. Para Rüsen (2010b), os especialistas estão de acordo quando reiteram a importância do livro didático no processo de ensino e aprendizagem de História,

\footnotetext{
${ }^{10}$ Disponível em: http://portal.mec.gov.br/busca-geral/318-programas-e-acoes-1921564125/pnld439702797/12391-pnld. Acesso em: 27 set. 2018.
} 
no entanto, poucos trabalhos abordam "o uso e o papel que os livros didáticos desempenham verdadeiramente no processo de aprendizagem em sala de aula" (RÜSEN, 2010b, p. 111).

No texto intitulado "O livro didático ideal", Jörn Rüsen (2010b), parte da sua teoria da aprendizagem histórica para sugerir um livro didático de História ideal, o qual possibilite a formação da consciência histórica dos alunos. Desse modo, ensaia uma proposta de estruturação do livro didático com base nas três dimensões da consciência histórica: experiência, interpretação e orientação. "A consciência histórica é ao mesmo tempo o campo de ação e objetivo da aprendizagem histórica" (RÜSEN, 2010b, p. 112). Nesse sentido, o livro didático de História ideal potencializa o desenvolvimento da experiência, interpretação e a orientação temporal no processo de ensino e aprendizagem de História, formando a consciência histórica das crianças e dos jovens na escola.

Assim, um livro didático ideal é aquele que promove a aprendizagem histórica e, portanto, possibilita a construção de uma consciência histórica, na qual $o$ aluno consegue perceber ao mesmo tempo $o$ passado na sua singularidade e nos seus resquícios com o presente, entendendo que este presente foi moldado pelas experiências ocorridas no passado, assim como, estas experiências servem como orientação dos indivíduos na vida em sociedade. Desta forma, é possível por meio do entendimento das relações complexas entre passado e presente, que se dão pela consciência histórica, analisar as qualidades necessárias para que um livro didático de História atenda as expectativas de orientação temporal e não apenas corresponda a um emaranhado de conteúdo sem significado para os estudantes (GERMINARI; MOURA, 2017).

\section{Considerações: ideias de professores}

Este texto buscou discutir questões relacionadas ao livro didático de História da "Coleção Novo Girassol: Saberes e Fazeres do Campo", indicado pelo PNLD Campo 2016 e utilizado pelos professores dos anos iniciais do Ensino Fundamental de um município próximo a cidade de Curitiba (PR).

Anteriormente foi apresentado um breve histórico sobre o ensino de História e as pesquisas sobre livros didáticos. A seguir, circunscreveu-se o PNLD 
Campo como o programa específico a ser analisado e foi apresentado o processo de seleção da coleção utilizada pelos professores. A seguir, serão apresentadas as considerações dos professores sobre o ensino de História e as perspectivas para a aprendizagem histórica e a relação com o livro didático de História selecionado.

O primeiro aspecto levantado pelos professores, desde o momento da escolha e confirmado posteriormente durante o trabalho pedagógico com os alunos, foi que tanto a coleção, de maneira geral, quanto o livro de História apresentam conteúdos e atividades de modo extremamente sintético. Toda a coleção é apresentada como integrada, isto é, todos os conteúdos apresentados devem estar conectados para uma melhor aprendizagem, de acordo com o que é descrito no Guia do Livro Didático do PNLD Campo. A grande crítica dos professores está no fato de que o pretexto da integração foi utilizado para apresentar um livro didático com poucas páginas e uma quantidade de conteúdo muito inferior ao de outras coleções. Os professores enfatizaram que a quantidade não significa diretamente qualidade, mas que o livro de História também contém conteúdo de Geografia e Letramento e Alfabetização. E, como exemplo, no segundo e terceiro anos são materiais consumíveis e os conteúdos de três áreas do conhecimento são apresentados em pouco mais de 200 páginas. É necessário salientar que o PNLD Campo oferece materiais didáticos em todas as áreas do conhecimento para alunos de todas as escolas do campo do Brasil e, sendo assim, um material enxuto como 0 apresentado dificulta 0 desenvolvimento do processo de ensino/aprendizagem.

Os professores afirmam que a integração dos conteúdos está presente nos títulos dos capítulos e nas atividades propostas no livro dos dois últimos anos do ciclo de alfabetização, em que os conteúdos são apresentados e desenvolvidos de forma progressiva, tendo o mesmo eixo. O material está dividido em: Minhas Vivências, Saberes e Fazeres da Terra e o Campo e suas Histórias. No $3^{0}$ ano, o capítulo Cidadão do Campo é adicionado aos já citados.

No quarto e quinto anos os temas para aprendizagem são exatamente os mesmos: Comunidade, Memória e História, Povo e Cultura, Campo: Tempo, Sujeitos e Histórias e Cidadania: Participação e Organização. Apesar da busca pela ampliação das discussões durante o passar dos anos, os professores 
relataram que a aprendizagem se tornou repetitiva devido ao fato de as atividades e propostas serem desconectadas com a realidade do aluno, já que, apesar de estar integrado com outros saberes, os conteúdos de História acabam não propondo atividades que dialoguem com o conhecimento do estudante, propiciando a construção do pensamento histórico.

Para o quarto e o quinto anos foi disponibilizado, também, um livro regional, cujo objetivo é a abordagem das questões locais e/ou regionais, devendo ser trabalhado de forma interdisciplinar. O PNLD Campo 2016 disponibilizou somente dois livros regionais, um intitulado "Coleção Tempo de Aprender", voltado para região norte do país, produzido pela Editora IBEP; e outro com título "Culturas e Regiões do Brasil", de conteúdo mais amplo com pretensões de abranger outras regiões do território nacional, da Editora Global, sendo este último enviado para as escolas participantes da pesquisa. Vale ressaltar que o material não foi para a escolha, apesar de ter sido analisado. 0 livro regional disponibilizado abrange questões de Arte, Cultura, História e Geografia. No entanto, o material, segundo os professores, não favoreceu o desenvolvimento do pensamento histórico do aluno, pois apresentou e propôs atividades que muitas vezes não levaram em conta a realidade do aluno e a construção do conhecimento histórico partindo da localidade.

Diante das discussões realizadas pelos professores, todos ressaltaram a necessidade do livro didático auxiliar nos processos de ensino/aprendizagem de modo significativo para os trabalhadores do campo. Desta maneira, quando os professores levantaram questões sobre a identidade do sujeito, apresentada nos materiais disponibilizados, foram ao encontro do que dizem as Diretrizes Curriculares da Educação do Campo do Estado do Paraná, que expressa: "O homem do campo não é atrasado e submisso; antes, possui um jeito de ser peculiar; pode desenvolver suas atividades pelo controle do relógio mecânico ou relógio 'observado' no movimento da terra, manifesto no posicionamento do sol" (PARANÁ, 2006, p. 29).

O conteúdo apresentado nos livros didáticos de História do PNLD Campo foi intensamente debatido por todos os professores, posto que ao analisarem de forma mais acurada o conteúdo, observaram que o material não levava em conta o modo de vida e o cotidiano das comunidades do município, concluindo, 
portanto, que não contribuem na promoção da compreensão da realidade e, consequentemente, não impulsionam a construção do pensamento histórico do aluno de modo significativo. De acordo com os professores, mesmo a coleção escolhida apresentou conteúdos não aprofundados e, de forma unânime, concordaram que precisariam propor atividades extras para suprir as questões não apresentadas pelo livro didático.

Todo o processo do PNLD, não só o do Campo, deveria ser repensado, visto que dois dos principais agentes do desenvolvimento e seleção do material didático, os autores e os professores, têm pouco tempo para construir um material que possa verdadeiramente atender as necessidades dos alunos e para avaliar, de forma profunda e consistente, o conteúdo de materiais que acompanharão os sujeitos integrantes do processo por vários períodos letivos. Mesmo tendo visão questionadora em relação à realidade do processo escolar e nos encontros com os professores ter construído uma visão crítica das coleções de livros didáticos oferecidos pelo PNLD Campo, o pouco tempo para o processo de escolha atrapalhou o processo de ensino/aprendizagem, pois sem uma análise anterior a dificuldade torna-se maior para o desenvolvimento de um trabalho que abarque o desenvolvimento do pensamento histórico e crítico dos alunos.

Ainda que sendo um Programa específico que tem como característica atender as especificidades das escolas localizadas no campo, a coleção disponibilizada e entregue às escolas e aos alunos se mostrou distante dos princípios da Educação do Campo. A continuidade do Programa poderia proporcionar o desenvolvimento de novos livros didáticos que atendessem as especificidades e necessidades de discussões para as escolas localizadas no campo, mas as modificações trazidas pelo Decreto 9.099, de 17 de julho de 2017 ${ }^{11}$ que transformou o PNLD em Programa Nacional do Livro e do Material Didático - PNLD também trouxe outras mudanças para os processos de seleção seguintes, sendo a principal delas a retirada da primazia da escolha, por parte do professor, do que será utilizado em sala de aula (artigo 18). Novas análises deverão ser realizadas para compreender como isso afetará os processos de ensino e aprendizagem. Para o PNLD 2019 não haverá o segmento PNLD Campo,

\footnotetext{
${ }^{11}$ Disponível em: http://www2.camara.leg.br/legin/fed/decret/2017/decreto-9099-18-julho-2017785224-publicacaooriginal-153392-pe.html. Acesso em: 27 set. 2018.
} 
logo não será possível investigar se o material desenvolvido especificamente para escolas localizadas no campo pode continuar a responder as necessidades educativas de seus alunos na área de História, e se promoverá o respeito a essa população.

O problema da presente pesquisa enquadra-se no campo de pesquisa em Educação Histórica, também denominada investigações em cognição histórica. $\mathrm{Na}$ atualidade, dois conceitos são centrais nessa área. De um lado a aprendizagem histórica é entendida a partir do conceito de pensamento histórico de tradição anglo-saxônica. Por outro lado, a aprendizagem histórica é compreendida como um processo da consciência histórica, conceito de tradição alemã. Ambos os conceitos, de modo isolado ou imbricado, alimentam as pesquisas em Educação Histórica no Brasil e em outros países. Antes de indicar diretamente os contornos do problema de pesquisa é necessário apresentar o domínio científico no qual ele se encontra, exercício necessário devido à complexidade dos conceitos de pensamento histórico e consciência histórica.

$\mathrm{Na}$ Inglaterra, país pioneiro nas pesquisas em Educação Histórica, o debate nas últimas décadas tem acontecido em torno de duas preocupações. $\mathrm{Na}$ primeira, professores, examinadores e pesquisadores concentram sua preocupação no significado e em como desenvolver a compreensão dos alunos na disciplina de História. Na segunda, alguns professores, muitos historiadores e o público leigo estiveram mais preocupados com o que os alunos deveriam saber sobre o passado no final dos seus estudos de História na escola.

Nos últimos anos, a Educação Histórica tem incorporado em suas pesquisas o conceito de consciência histórica, na perspectiva do historiador alemão Jörn Rüsen. Acerca dessa incorporação, Lee reconhece que a ideia de consciência histórica possibilita a reconceitualização do campo de investigação, pois,

\footnotetext{
"A consciência histórica" sugere uma perspectiva teórica integrativa capaz de subordinar duas tendências relacionadas, e talvez uma tradição bastante diferente. Ela traz a perspectiva de convergência entre o crescente interesse mostrado por muitos historiadores naquilo que pode ser chamado "memória" e o foco do ensino de História nas imagens que os estudantes têm do passado. (LEE, 2002, p. 1).
} 
Essas investigações tiveram origem na Alemanha. A utilização do conceito de consciência histórica no ensino de História emergiu das discussões entre especialistas em didática da antiga RDA (República Democrática Alemã) e RFA (República Federal da Alemanha), na década de 1980.

Nessa perspectiva, o pesquisador Peter Lee (2006) enfatiza que a Educação Histórica, referenciada na ciência da História, precisa caminhar em direção a uma noção utilizável de literacia histórica que alia, por um lado, a compreensão acerca da disciplina de História e, por outro lado, algum conhecimento substantivo acerca do passado significativo que permita, ao aluno, atribuir sentido ao presente e ao futuro.

A definição do conceito de literacia histórica, delineada por Peter Lee (2006), sustenta-se em considerações de filósofos da História ${ }^{12}$, acerca da natureza do conhecimento histórico e em resultados de pesquisas empíricas realizadas com crianças e jovens de escolas britânicas. A investigação concernente à literacia histórica tem se concentrado em componentes principais: a) levantamento e compreensão das ideias dos estudantes acerca da disciplina de História; b) pesquisa acerca das orientações dos estudantes em direção ao passado (tipos de experiências do passado acessadas pelos estudantes) e c) os sentidos estabelecidos em relação ao presente e ao futuro, em outras palavras, investiga-se os sentidos históricos criados pelas crianças e jovens no âmbito escolar. Nesse sentido, pode-se afirmar que os livros didáticos do PNLD Campo analisados pelos professores ainda estão longe de fazer sentido histórico para os alunos, pois não reconhecem as carências de orientação temporal.

Peter Lee (2006) introduz o conceito de sentido histórico com base na perspectiva de Jörn Rüsen ${ }^{13}$, o qual coloca o sentido histórico como elemento central da aprendizagem histórica, entendida como "[...] a consciência humana relativa ao tempo, experimentando o tempo para ser significativo, adquirindo e desenvolvendo a competência para atribuir significado ao tempo" (RÜSEN, 2010a, p. 79).

\footnotetext{
12 O artigo "Em direção a um conceito de literacia histórica", publicado no periódico Educar em Revista, em 2006, dialoga com os filósofos da História: Bevir, Collingwood, Lorenz, Oakeshott e Rüsen.

${ }^{13}$ Ver: (RÜSEN, 1993).
} 
Para Rüsen (2001), a consciência histórica articula cognitivamente o passado, o presente e o futuro em uma estrutura narrativa dotada de sentido cuja função é oferecer orientação temporal para a existência humana. Tal operação mental realiza-se por meio da interpretação das experiências do passado, as quais são motivadas com a intenção de superação das carências de orientação temporal no presente.

A consciência histórica pode ser descrita como "[...] o trabalho intelectual realizado pelo homem para tornar suas intenções de agir em conformidade com a experiência do tempo. Esse trabalho é efetuado na forma de interpretações das experiências do tempo. Estas são interpretadas em função do que se tenciona para além das condições e circunstâncias dadas da vida" (RÜSEN, 2001, p. 59), o resultado desse trabalho mental é o estabelecimento de sentidos históricos (articulação passado, presente e futuro) que orientam o agir na vida prática.

Deste modo, os materiais didáticos de História contribuem para o desenvolvimento de relações temporais quando buscam interação com as experiências vividas pelos alunos. Os livros analisados estão recheados de exemplos de distanciamento da realidade dos alunos. Para citar apenas um caso, o livro do terceiro ano propõe uma atividade para pesquisar nomes de ruas, no entanto, a maioria das ruas das comunidades localizadas no campo, no município, não possui nome oficial, o que impossibilita a realização da atividade e demonstra a falta de relação com a realidade local.

No geral, os processos históricos apresentados no livro didático não privilegiam a articulação entre presente, passado e futuro. Isso é uma relação que é deixada para o professor e, por vezes, o modelo de futuro apresentado é o urbano, dificultando o trabalho de formação da consciência histórica, compreendida como objetivo da aprendizagem histórica. Rüsen (2007, 2012), entende a consciência histórica como um processo de aprendizagem histórica, pois o ato de interpretar a experiência do passado, para compreender o presente e perspectivar o futuro de modo a orientar as ações na vida prática, pode ser caracterizado como a geração de um aprendizado histórico.

Ainda nessa direção, a relação com tempo realizada na consciência humana é compreendida como um processo de aprendizagem porque orienta o indivíduo nas questões temporais que afetam sua vida. Essa função essencial ocorre em 
dois aspectos: orientação temporal da vida prática externa e interna. A orientação temporal externa relaciona-se à práxis e a interna à formação da identidade histórica.

Os conteúdos apresentados estão longe de potencializar a aprendizagem histórica na perspectiva de Rüsen $(2007,2012)$, pois os nexos temporais não estão no centro da proposta de aprendizagem e as relações com as identidades dos alunos são frágeis. A relação com o tempo, em todos os volumes do livro, não apresenta atividades e nem proporciona a construção de relações com o tempo no espaço rural. O tempo apresentado no livro didático é o tempo capitalista, medido pelo relógio, e o tempo da natureza, o qual, muitas vezes, rege a vida no campo, não é considerado para construir relações temporais, somente quando se estuda linhas temporais que ainda são muito utilizadas. Os professores não reconhecem o livro como material adequado para desencadear processos de ensino/aprendizagem de histórias úteis para os alunos. Na visão de Forquin (1993, p. 9), na prática docente

[...] ninguém pode ensinar verdadeiramente se não ensina alguma coisa que seja verdadeira ou válida a seus próprios olhos. Esta noção do valor intrínseco da coisa ensinada [...] está no próprio centro daquilo que constitui a especificidade da intenção docente como projeto de comunicação formadora.

Assim, ensinar e aprender História, de modo significativo para o aluno, significa desenvolver a capacidade de orientação temporal, mediando às operações essenciais da consciência histórica.

\section{Referências}

BITTENCOURT, Circe Maria Fernandes. Livro didático e conhecimento histórico: uma história do saber escolar. 1993. 369 f. Tese (Doutorado em Educação) Universidade de São Paulo, São Paulo, 1993.

BITTENCOURT, Circe Maria Fernandes. Livros didáticos entre texto e imagens. In: BITTENCOURT, Circe Maria Fernandes. (org.). O saber histórico na sala de aula. São Paulo: Contexto, 1997. p. 69-90.

BITTENCOURT, Circe Maria Fernandes. Ensino de história: fundamentos e métodos. São Paulo: Cortez, 2008. 
BITTENCOURT, Circe Maria Fernandes. Produção didática de história: trajetórias de pesquisas. Revista de História, São Paulo, n. 164, p. 487-516, jan./jun. 2011.

BRASIL. Constituição da República Federativa do Brasil de 1988. Brasília. Disponível em:

http://www.planalto.gov.br/ccivil_03/constituicao/constituicao.htm. Acesso em: 25 set. 2018.

CHAVES, Edilson Aparecido. A presença do livro didático de história em aulas do ensino médio: estudo etnográfico em uma escola do campo. 2015. 226 f. Tese (Doutorado em Educação) - Universidade Federal do Paraná, Curitiba, 2015.

FERRO, Marc. Manipulação da história no ensino e nos meios de comunicação. Tradução de Wladimir Araújo. São Paulo: Ibrasa, 1983.

FONSECA, Thais Nivia de Lima. História e ensino de história. Belo Horizonte: Autêntica Editora, 2011.

FORQUIN, Jean-Claude. Escola e cultura: as bases sociais e epistemológicas do conhecimento escolar. Porto Alegre: Artes Médicas, 1993.

GERMINARI, Geyso Dongley. O ensino de história local e formação da consciência histórica: possibilidades. Quaestio, Sorocaba, SP, v. 18, n. 3, p. 761-776, nov. 2016.

GERMINARI, Geyso Dongley; GONÇALVES, Rita de Cássia. As políticas educacionais e formação do professor de História no Brasil: desafios contemporâneos. Interacções, Lisboa, v. 12, n. 40, p. 55-69, 2016.

GERMINARI, Geyso Dongley; MOURA, Anderson Fagundes. Livro didático de história, entre conteúdos e epistemologia. Educação Unisinos, São Leopoldo, RS, v. 21 , n. 1, p. 102-110, jan./abr. 2017.

LEE, Peter. 'Caminhar para trás em direção ao amanhã': a consciência histórica e o entender da história. Tradutor de: SOARES, José Norberto. In: ENCONTRO ANUAL DA ASSOCIAÇÃO AMERICANA DE PESQUISA EM EDUCAÇÃO. New Orleans. 2002. p. 1-45. Disponível em:

https://www.history.org.uk/files/download/9227/1319458921/IJHLTR_4.1.pdf. Acesso em: 26 mar. 2014.

LEE, Peter. Em direção a um conceito de literacia histórica. Educar, Curitiba, Especial, p. 131-150, 2006.

MUNAKATA, Kazumi. Produzindo livros didáticos e paradidáticos. 1997. 217 f. Tese (Doutorado em Educação) - Pontifícia Universidade Católica de São Paulo, São Paulo, 1997.

MUNAKATA, Kazumi. História que os livros didáticos contam, depois que acabou a ditadura no Brasil. In: FREITAS, M. C. de. (org.). Historiografia brasileira em perspectiva. São Paulo: Contexto, 2010. p. 271-296. 
MUNAKATA, Kazumi. O livro didático: alguns temas de pesquisa. Rev. Bras. Hist. Educ., Campinas, SP, v. 12, n. 3 (30), p. 179-197, set./dez. 2012.

MUNARIM, Antonio. Prefácio. In: MUNARIM, Antonio et al. Educação do campo: reflexões e perspectivas. Florianópolis: Insular, 2010. p. 9-18.

OLIVEIRA, Itamar Freitas et al. A ação do PNLD em Sergipe e a escolha do livro didático de história (2005/2007): exame preliminar. In: OLIVEIRA, Margarida Maria Dias; STAMATTO, Maria Inês Sucupira. Livro didático de história: políticas educacionais, pesquisa e ensino. Natal: EDUFRN, 2007. p. 53-59.

OLIVEIRA, João Batista Araújo. A política do livro didático. São Paulo: Summus, 1984.

PARANÁ. Secretaria de Estado da Educação. Diretrizes curriculares da Educação do campo. Curitiba: SEED, 2006.

RÜSEN, Jörn. Experience, interpretation, orientation: there dimensions of historical learning. In: DUVENAGE, P. (ed.). Studies in metahistory. Pretoria: Human Sciences Research Council, 1993.

RÜSEN, Jörn. Razão histórica: teoria da história. Os fundamentos da ciência histórica. Brasília: Editora da Universidade de Brasília, 2001.

RÜSEN, Jörn. História viva: teoria da história III. Formas e funções do conhecimento histórico. Brasília: Editora da Universidade de Brasília, 2007.

RÜSEN, Jörn. Experiência, interpretação, orientação: três dimensões da aprendizagem história. In: SCHMIDT, Maria Auxiliadora Moreira dos Santos; BARCA, Isabel; MARTINS, Estevão de Resende. Jörn Rüsen e o ensino de história. Curitiba: Editora UFPR, 2010a. p. 79-91.

RÜSEN, Jörn. O livro didático ideal. In: SCHMIDT, Maria Auxiliadora Moreira dos Santos, BARCA, Isabel; MARTINS, Estevão de Resende. Jörn Rüsen e o ensino de história. Curitiba: Editora UFPR, 2010b. p. 109-127.

RÜSEN, Jörn. Aprendizagem histórica: fundamentos e paradigmas. Curitiba: W. A. Editores, 2012.

SANTOS, Rita de Cássia Gonçalves Pacheco. A significância do passado para professores de história. 2013. 262 f. Tese. (Doutorado em Educação) Universidade Federal do Paraná, Curitiba, 2013.

TIMBÓ, Isaíde Bandeira. Livro didático de história e a formação docente: uma reflexão necessária. In: OLIVEIRA, Margarida Maria Dias de; STAMATTO, Maria Inês Sucupira. Livro didático de história: políticas educacionais, pesquisa e ensino. Natal: EDUFRN, 2007. p. 61-73.

ZAMBONI, Ernesta. Encontros Nacionais de Pesquisadores de História: pesquisadores de histórias: perspectivas. In: ENCONTRO NACIONAL DE 
PESQUISADORES DE ENSINO DE HISTÓRIA, 2005, Londrina. Anais [...]. Londrina: Atrito Art, 2005. p. 37-49. 